\title{
Animal ethics and welfare education in wet-lab training can foster residents' ethical values toward life
}

\author{
Yuko IKI ${ }^{1)}$, Takuya ITO ${ }^{1,2)}$, Katsuyoshi KUDO ${ }^{1,3)}$, Masafumi NODA ${ }^{1,4)}$, Masahiko KANEHIRA ${ }^{1,4)}$, \\ Teruko SUETA $^{5)}$, Ichiro MIYOSHI ${ }^{5}$, Yutaka KAGAYA ${ }^{6}$, Yoshinori OKADA ${ }^{4)}$, and Michiaki UNNO ${ }^{1,3)}$ \\ 1) Tohoku University Hospital Advanced Medical Training Center, 2-1 Seiryo-cho, Aoba-ku, Sendai, Miyagi 980- \\ 8575, Japan \\ 2) International Disciplinary Biomedical Engineering, Course of Disability Science, Tohoku University Graduate \\ School of Medicine, 2-1 Seiryo-cho, Aoba-ku, Sendai, Miyagi 980-8575, Japan \\ 3) Division of Gastroenterological Surgery, Department of Surgery, Tohoku University Hospital, 1-1 Seiryo-cho, \\ Aoba-ku, Sendai, Miyagi 980-8575, Japan \\ 4) Department of Thoracic Surgery, Tohoku University Hospital, 2-1 Seiryo-cho, Aoba-ku, Sendai, Miyagi 980-8575, \\ Japan \\ 5) Institute for Animal Experimentation, Tohoku University Graduate School of Medicine, 2-1 Seiryo-cho, Aoba-ku, \\ Sendai, Miyagi 980-8575, Japan \\ ${ }^{6)}$ Comprehensive Education Center for Community Medicine, Tohoku University Graduate School of Medicine 2-1 \\ Seiryo-cho, Aoba-ku, Sendai, Miyagi 980-8575, Japan
}

\begin{abstract}
Live animals are used in surgical skills training in wet lab, which has undeniable effectiveness for the development of future surgeons. However, where such training is provided, animal welfare is a major consideration. Increasingly, institutions that offer wet-lab training are incorporating animal ethics and welfare-related content into their training courses, but the effectiveness of such animal ethics education has yet to be evaluated quantitatively. We investigated whether the animal ethics content of a training course affected trainees by measuring increase in ethical awareness using visual analog scale questionnaires before and after training. Our results demonstrated a significant and positive increase in awareness of animal ethics (significance level of $5 \% ; 0.0380 \leq P \leq 0.0016$ ).
\end{abstract}

Key words: animal ethics, resident, self-efficacy, visual analog scale, wet-lab training

\section{Introduction}

Wet labs play a role in development of surgical skill through the utilization of live animals. In their wet-lab training, doctors use animals from medium-to-large species, such as pigs, to help in acquiring surgical skills.

Originally, training on surgical techniques was delivered by a senior physician in the clinical setting, in a room closed to the outside. Nowadays, however, this training can take place in a Simulation Center (dry lab) or in a training center with live animals from a medium- to-large species (wet lab). A characteristic of these forms of training is that the locations are not closed and observers can easily offer comments and opinions. Wet-lab training is closer to actual clinical practice than some other training forms and has a greater resemblance to real technical training, as living organisms are used. Wetlab training also enables the acquisition of the soft skills that a surgeon may need, as the situation fosters nontechnical skills such as communication skills, mental fortitude, and teamwork. Wet-lab training is accordingly very useful and effective for young surgeons and

(Received 2 March 2017 / Accepted 10 May 2017 / Published online in J-STAGE 7 June 2017)

Address corresponding: T. Ito, Tohoku University Hospital Advanced Medical Training Center, 2-1 Seiryo-cho, Aoba-ku, Sendai, Miyagi 980-8575, Japan

C2017 Japanese Association for Laboratory Animal Science 
trainee doctors who have yet to perform a real operation $[1,8-10]$. However, animal welfare has become a major concern in today's world, and modern society is expected to critically examine any training that uses animals, depending on the manner in which it is conducted $[4,7,11]$.

In wet labs in Japan today, it is recognized that, from a moral viewpoint, some formal education on animal ethics and welfare should be provided to trainees before they start technical training using animals. However, doctors tend to have very full schedules and so the duration of training is often limited to one day. Education on animal ethics and welfare must be delivered as a mandatory topic within a short amount of this valuable training time, and to trainees who may regard it as irrelevant to their needs. Continuing to include animal ethics education as part of technical training courses requires confidence in the effectiveness of this education. Nevertheless, the psychological impact of this education on doctors attending training courses has not been investigated.

The Tohoku University Advanced Medical Training Center (TAMTC) held a training course titled "Surgical Skills Training for Junior Residents Using Live Pigs under General Anesthesia" between 2014 and 2016. This training course was approved by the Animal Research Advisory Panel of the university's Environmental Safety Committee (Approval No. 2013MdE-004). In the present study, we aimed to investigate the effectiveness of this training using data obtained from the trainees with their consent. The data were obtained from the trainees at the same time as self-efficacy measurements before and after this training course, which covered 10 topics related to surgical procedures. Our previous study reported that the wet-lab including animal ethics lecture and the observation of animal care by animal technicians verified participants' psychological movements [6]. However, it has not clearly proven yet whether this psychological movement induced to raise ethical awareness against all life on earth, including animals.

We set out to analyze the training-induced change in awareness of animal ethics using these data.

\section{Materials and Methods}

\section{Training course content}

Participants in the TAMTC course "Surgical Training for Junior Residents using Pigs under General Anesthe- sia" were asked to complete questionnaires before and after the training. Study subjects were 41 junior physicians who were in their first (R1) or second (R2) year of residency between September 2014 and February 2016. The subjects completed questionnaires three times: when they applied for the training, immediately before the training course, and after completion of the training course. Questionnaire completion was not obligatory, it was stated that the entered information could only be used for educational purposes, and consent for use of the data was obtained.

As part of the TAMTC training course, a 30-minute session on animal welfare and the ethics of animal use was included in the morning lectures. This session was used to promote awareness of the animals as living beings. Another feature of this TAMTC training course was a 15-minute session before the start of the afternoon surgical practice. This session involved observation of animals receiving agents for preemptive analgesia and sedation in their pens and then being transferred to the operating room under the supervision of animal care technicians. The policy of the Tohoku University Medical Department's Animal Research Facility stipulates a 2-week acclimation period for pigs to be used by TAMTC. Furthermore, the technicians who regularly provide animal care in the facility are to carry out procedures on the day of training, so that the training can be carried out smoothly without causing fear or stress for the animals.

\section{Questionnaires}

Changes in personal ethical awareness are difficult to quantify numerically. Accordingly, we used a highly sensitive evaluation scale, the visual analog scale (VAS) for the questionairres $[2,3,5-7,10]$. The VAS is used in clinical settings to assess pain, and contains a straight, horizontal $10-\mathrm{cm}$ line, along which respondents make a vertical mark corresponding to a grade for the matter being surveyed (Fig. 1). We attempted to quantify the effectiveness of the training numerically, using the differences between grades entered before and after training. The extreme left of the scale represented a response of "Strongly disagree" and the extreme right of the scale represented a response of "Strongly agree". The questionnaire was administered to study subjects two times on the day of the training, once in the morning as they gathered for the training and once immediately after the completion of training, and contained the same items on 
Q. Do you think that health professionals should have a stronger moral compass compared with non-health professionals?

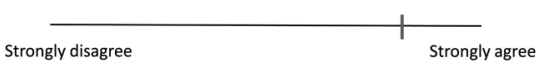

Fig. 1. Example of the Visual Analog Scale (VAS). This VAS consists of a $10-\mathrm{cm}$ horizontal line. The respondent indicates his or her response by making a vertical mark on the VAS. The range of the VAS is from 0 to $10 \mathrm{~cm}$, left to right (minimum to maximum). Responses (in $\mathrm{cm}$ ) were rated to the first decimal place.

both occasions.

We deliberately mixed questions related to animal ethics with questions on matters likely to be unaffected by the training when designing the questionnaire. This enabled us to use the responses to the non-training-related questions as benchmarks for comparison with the animal ethics-related responses. Benchmark questions were related to awareness of human ethics, and the target questions were related to awareness of animal ethics. TAMTC wet-lab training does not cover awareness of human ethics. We devised 11 ethics-related questions, of which five were benchmark questions and six were target questions. The questions were arranged in random order.

People form a sense of ethics with their personal development, and the number of factors that may affect an individual's basic values are potentially limitless. Accordingly, we expected it would be difficult to estimate the effect of one-time training and that there would be wide variation among the study subjects. Therefore, we asked study subjects about two attributes that might be expected to influence the evaluation results: previous history of pet ownership (the specific question was "Did you have a pet when you were growing up?") and previous history of animal-related training (the specific question was "Have you received training related to large animals at another institution?"). We also evaluated the responses from study subject classified with each of these attributes.

Pigs used in TAMTC training become very familiar with the animal care technicians through the (pre-training) acclimation period. We surveyed the study subjects (participating doctors) on their understanding of the need for acclimation. This question was administered as a set of eight possible reasons for acclimation, from which study subjects had to select two. The options belonged to two categories: emotional reasons and practical reasons (such as assuring the scientific validity of the training, meeting social standards, and improving ease of animal handling during the training).

\section{Verification of question content}

The definition of "ethics" itself falls within the scope of research, and ethics-related questions are inherent difficult to devise. Accordingly, it needs to be verified that such questions accord with the intention of the survey. The pre- vs. post-training differences in survey responses to ethics-related questions were subject to a factor analysis to verify that the questions we devised were consistent with the objective of this survey.

\section{Statistical analyses}

The differences in study subjects' feelings between pre- and post-training were measured using the VAS, and assumed to represent the effect of the training, for a numerical assessment. The obtained data were analyzed with Mac Statistical Analysis, Ver. 2.0 (Esumi Co., Ltd., Tokyo, Japan). The data were paired data and the minimum sample size was 30 . Data from pre- and posttraining were analyzed for homogeneity of variance and normal distribution with statistical testing of differences in population mean using an F-test, the Shapiro-Wilk test, and the Kolmogorov-Smirnov test. The results were analyzed using the Wilcoxon signed-rank test.

Absolute values were used for the pre- vs. post-training differences in study subjects with a history of pet ownership and those with a history of large animal-related training. These differences were not analyzed for direction of change (positive or negative). We also performed a factor analysis to verify that the questions accorded with the intention of the survey. The significance level for these analyses was set at $5 \%$.

\section{Results}

Differences in response between pre- and post-training were evaluated for significance using the Wilcoxon signranked test. The responses to six questions related to animal ethics and to five questions related to human ethics were evaluated, with the significance level set at $5 \%$. The responses to all six animal ethics-related questions differed significantly between pre- and post-training $(0.0380 \leq P \leq 0.0016)$; however, only one of the human ethics-related questions yielded a significant difference 
Table 1. Questionnaire responses - actual values and results of analysis by Wilcoxon signed rank test

\begin{tabular}{|c|c|c|c|c|c|c|c|c|}
\hline $\begin{array}{l}\text { Question } \\
\text { No. }\end{array}$ & $\begin{array}{c}\text { No. of } \\
\text { Responses }\end{array}$ & Mean & Median & $\begin{array}{l}\text { Maximum } \\
\text { Value }\end{array}$ & $\begin{array}{l}\text { Variance } \\
\quad \text { (n) }\end{array}$ & $\begin{array}{l}\text { Sign-rank } \\
\text { result }\end{array}$ & $P$ value & Question Content \\
\hline 1 & 41 & 0.54 & 0.2 & 3.4 & 1.92 & $*$ & 0.0137 & $\begin{array}{l}\text { Do you agree that physicians have a stronger } \\
\text { sense of ethics than other people? }\end{array}$ \\
\hline $2 \dagger$ & 41 & -0.49 & 0 & 1.7 & 1.32 & $*$ & 0.0218 & $\begin{array}{l}\text { Do you agree that a physician's sense of } \\
\text { ethics concerns people but not animals }\end{array}$ \\
\hline 3 & 40 & 0.79 & 0.23 & 4.3 & 2.44 & $* *$ & 0.005 & $\begin{array}{l}\text { Do you agree that ethical viewpoints toward } \\
\text { people and animals should be the same? }\end{array}$ \\
\hline 4 & 40 & 0.27 & 0 & 5.9 & 1.71 & & 0.4822 & $\begin{array}{l}\text { Do you agree that ethical awareness of people } \\
\text { is fostered by direct contact with patients? }\end{array}$ \\
\hline 5 & 41 & 0.31 & 0.1 & 7.5 & 6.9 & & 0.2232 & $\begin{array}{l}\text { Do you agree that medical department classes } \\
\text { instill a sufficient sense of ethics? }\end{array}$ \\
\hline 6 & 41 & 0.18 & 0 & 5.5 & 1.51 & & 0.4711 & $\begin{array}{l}\text { Do you agree that a sense of ethics is } \\
\text { indispensable for a physician? }\end{array}$ \\
\hline 7 & 41 & 0.61 & 0.35 & 7 & 5.38 & $*$ & 0.0287 & $\begin{array}{l}\text { Did you feel any mental hesitation during the } \\
\text { training and animal experimentation? }\end{array}$ \\
\hline 8 & 41 & 0.58 & 0.6 & 5 & 4.51 & $*$ & 0.038 & $\begin{array}{l}\text { Did the training and animal experimentation } \\
\text { strengthen your self-awareness as a physician? }\end{array}$ \\
\hline 9 & 40 & 0.81 & 0.2 & 5.4 & 2.46 & $* *$ & 0.0016 & $\begin{array}{l}\text { Do you agree that animal experimentation and } \\
\text { training provide an opportunity to consider } \\
\text { animal ethics? }\end{array}$ \\
\hline $10 \dagger$ & 41 & -0.48 & 0 & 2.3 & 1.46 & $*$ & 0.0202 & $\begin{array}{l}\text { Do you agree that humans are the subjects of } \\
\text { an ethical viewpoint but animals are not? }\end{array}$ \\
\hline 11 & 41 & 0.12 & 0.05 & 5.7 & 4.38 & & 0.2137 & $\begin{array}{l}\text { Do you agree that physicians should aim to } \\
\text { be skilled and highly ethical? }\end{array}$ \\
\hline
\end{tabular}

$\uparrow$ : Questions 2 and 10 were designed to prevent habitual responses and were accordingly targeting responses in the opposite direction to other questions. Significant results in signed rank test shown by [*] $0.01<P<0.05$, [**] $P<0.01$. Cells shaded in grey are animal ethicsrelated questions.

$(P=0.0137)$. The direction of change was toward greater ethical awareness (Table 1).

Absolute pre- vs. post-training differences were analyzed for study subjects with attributes that might have influenced the outcome. No significant difference in absolute mean values was found for study subjects with a history of pet ownership $(P=0.663)$ or study subjects with a history of large animal-related training $(P=0.4436)$. Accordingly, the null hypothesis (that training had no effect on awareness of animal ethics) could not be rejected for study subjects with either of these attributes.

The results for study subject (participating doctors) recognition of the need for acclimation are shown in Table 2. Large numbers of respondents felt there were practical reasons for the effectiveness of acclimation, as follows: 24 subjects agreed that "Acclimated animals are easier to handle", 21 subjects agreed that "Acclimation mitigated animal ethics problems", and 11 subjects agreed that "Acclimation improved vital data during training". Small numbers of respondents selected emotional reasons for acclimation, as follows: four subjects agreed that "Acclimation reduces feelings of guilt concerning animal sacrifice", and six subjects agreed that "Acclimation reduced feelings of guilt concerning animal handlers".

Factor analysis that aims to find independent latent variables was performed to verify the nature of the questions, and the results are shown with two directional axes (Fig. 2). What variable affects on each dimensional axis is presumed by the contribution rate of each question result. By the observation of high contribution rate's question, the variable, that is axis name, is elicited. Responses which loaded highly onto Axis-1, which represented Factor 1, were those for Question 7 [Did you feel any mental hesitation during the training and animal experimentation? (factor loading $=0.9922$ )] and Question 8 [Did the training and animal experimentation strengthen your self-awareness as a physician? (factor loading $=0.5784)$ ]. The responses along Axis-1 from that for Question 6 [Do you agree that a sense of ethics is indispensable for a doctor? (factor loading $=-0.3395$ ) suggest an awareness of "life", an essential ethical 
Table 2. Cross tabulation for responses on reason for acclimation (2 selections requested)

\begin{tabular}{|c|c|c|c|c|c|c|c|c|c|}
\hline \multirow{2}{*}{$\begin{array}{l}\text { Option } \\
\text { No. } 1\end{array}$} & & \multirow{2}{*}{ Aggregate } & \multicolumn{6}{|c|}{ Mean absolute difference $(0.00 \leq X \leq 2.78)$} & \multirow{2}{*}{ Question Content } \\
\hline & & & 0 to 0.5 & 0.5 to 1 & 1 to 1.5 & 1.5 to 2 & 2 to 2.5 & 2.5 to 3 & \\
\hline 1 & Total & 4 & 1 & 1 & 0 & 1 & 1 & 0 & $\begin{array}{l}\text { Acclimation reduces feelings of guilt concerning animal } \\
\text { sacrifice }\end{array}$ \\
\hline 2 & & 7 & 1 & 1 & 1 & 2 & 1 & 1 & Acclimation surmised to have some scientific basis \\
\hline 3 & & 24 & 8 & 4 & 4 & 3 & 5 & 0 & Acclimated animals are easier to handle in practice \\
\hline 4 & & 21 & 5 & 2 & 6 & 2 & 5 & 1 & Acclimation mitigates animal ethics problems \\
\hline 5 & & 6 & 0 & 0 & 3 & 2 & 1 & 0 & $\begin{array}{l}\text { Acclimation reduces feelings of guilt concerning animal } \\
\text { handlers }\end{array}$ \\
\hline 6 & & 11 & 3 & 4 & 1 & 1 & 2 & 0 & Acclimation improves biological handling during training \\
\hline 7 & & 0 & 0 & 0 & 0 & 0 & 0 & 0 & Acclimation has no benefit \\
\hline 8 & & 2 & 0 & 0 & 1 & 0 & 1 & 0 & Not applicable (free entry) \\
\hline
\end{tabular}

Respondents selected 2 of 8 possible reasons for acclimation stated on the questionnaire. Absolute pre- vs. post-training differences were represented in a histogram with unit intervals of 0.5 , and no. of respondents selecting a reason for acclimation were entered. Shaded cells represent an emotional reason for acclimation. Other cells represent a practical reason for acclimation, such as assuring scientific validity, meeting social standards, and improving ease of animal handling during the training.

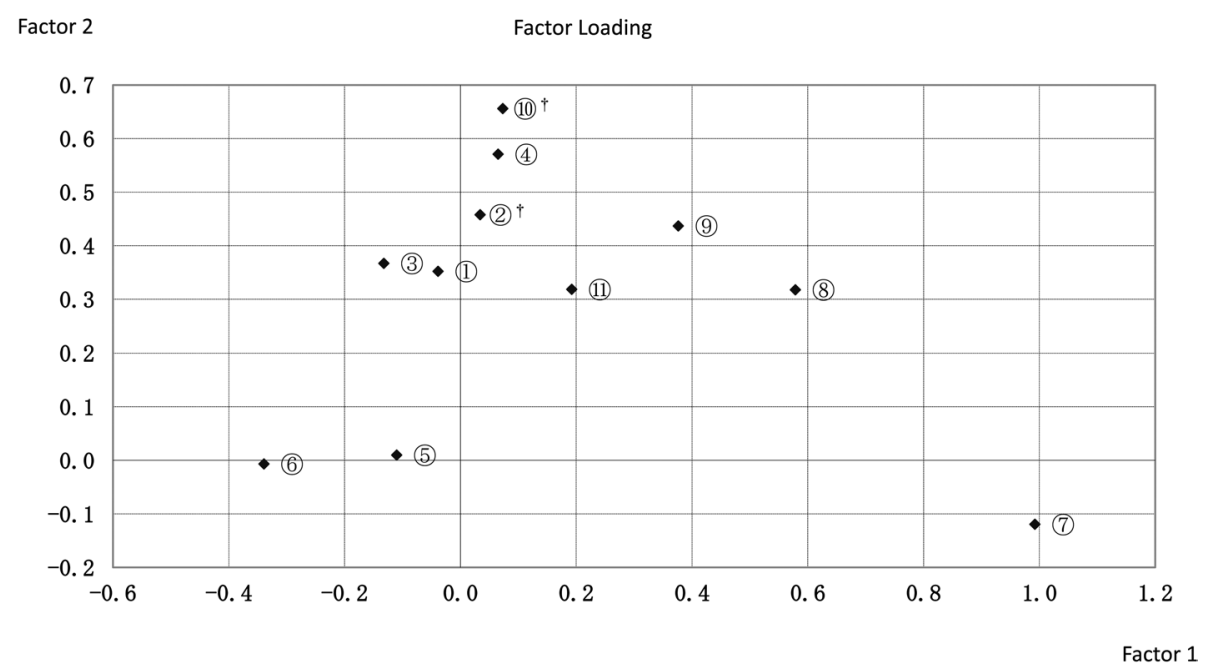

Fig. 2. Factor analysis for all ethics-related responses - with factor loading. The cluster of high contribution rate's questions onto each axis elicits the variable, so-called the name of axis. The name of axis shows how designed the content of questions in order to find examinee's psychology. $\dagger$ : Questions 2 and 10 were designed to prevent habitual responses and accordingly targeted responses in the opposite direction to the other questions; therefore, measured values were adjusted by subtraction from the maximum VAS value.

awareness that both humans and animals are living beings. The questionnaire responses loading highly onto Axis-2 (for the underlying Factor 2) were those for Question 10 [Do you agree that people are the objects of an ethical viewpoint but animals are not?" (factor loading $=0.6556$ )], Question 4 [Do you agree that ethical awareness of people is fostered by direct contact with patients? (factor loading $=0.5705$ )], and Question 2 [Do you agree that a physician's sense of ethics concerns people but not animals? (factor loading $=0.4575)]$. The questions yielding high Axis-2 loading (for underlying Factor 2) responses were concerned with separation of approach to human and animal ethics. These responses indicated an awareness of species.

\section{Discussion}

Animal welfare awareness has been growing since the 
1900s, with European countries at the forefront. The initial assumption driving this movement concerned a lack of awareness of animal ethics among animal handlers. Wet labs are used in the training of surgeons, and perceptions of wet labs may vary from country to country. However, wet labs form part of the modern surgical training process and, barring actual clinical practice, are felt to be ideal places for training. Wet labs have a number of characteristics which assist in the goal of successfully and consistently training surgeons. Comprehensive training on all the complex and interlinked aspects of surgery is possible; anxiety is kept to a moderate level appropriate for training and does not become excessive; and a young generation of doctors can gain practical experience of surgical procedures before becoming surgeons. As a simplification, wet labs are places where the training effect is produced from a living animal; therefore, participants in wet-lab training courses must be constantly aware of animal ethics and welfare. Naturally, this is a social and moral obligation, but heightening the awareness of "life" should be prioritized in the training of physicians.

This survey was aimed to achieve a numerical assessment as part of the checking stage of the Plan-Do-CheckAct cycle, which should be a widely adopted concept in medical training. This was an assessment of whether the training course content accorded with the intention of the course organizers.

TAMTC incorporates awareness of animals as living beings into its wet-lab training as far as possible because live pigs are used in the training. Accordingly, we can expect that wet labs will be used for the fostering of ethical awareness in young physicians, in particular junior residents. We set out to determine whether this training was actually having the effect on junior residents that its organizers intended, by analyzing pre- and posttraining data with the Wilcoxon sign ranked test. Questionnaire items used to obtain these data were classified into two categories, with six animal ethics-related questions and five human ethics-related questions. The responses to all six animal ethics-related questions showed a significant difference between pre- and post-training, with the direction of change being toward greater ethical awareness. By contrast, the responses to human ethicsrelated questions, which addressed an area not covered in the training course, showed a significant difference for only one question. These results indicate that the course content sufficiently increased the participants' awareness of animal ethics, even though only $45 \mathrm{~min}$ were spent promoting the concept of animals as living beings. These results also showed that subjects with a history of pet ownership or large animal-related training were not influenced by the ethics education.

"Ethics" was the theme of this training, but it is a very difficult word to define exactly, and the nature of the questions in our survey needed to be verified. Accordingly, our basic approach was to devise questions that enabled recognition of the object of an ethical viewpoint. In Fig. 2, we submitted the pre- and post-training differences in questionnaire responses to a factor analysis to check the nature of the questions. Based on the results for Axis-1, we concluded that an ethically based awareness of "life" as belonging to all species influenced study subjects' responses as Factor 1. Factor 2 was suggested to be the influence on study subjects' responses of an awareness of species (separating humans and animals as objects of an ethical viewpoint). Based on the results of this factor analysis, we concluded that the questions devised accorded with the objective of the survey.

The effectiveness of the wet-lab training held at TAMTC was measured from questionnaire responses on animal ethics and confidence on 10 surgical procedures before and after the training. At the completion of training, participants were asked to complete an integrated questionnaire which surveyed their satisfaction with the training course and their views on animal ethics. The questionnaire used a VAS for both the items related to animal ethics and those related to course satisfaction. The average score for satisfaction with the course was 9.1 (where 10 represented the maximum possible satisfaction on the VAS) among the 25 participants who responded to all the animal ethics-related items and all the course evaluation-related items on the questionnaire. We used Spearman's rank correlation coefficient to test for a relationship between improvement in the 10 surgical procedure-related items and the mean degree of satisfaction with the course, and although we found no monotonic relationship $(P=0.2622)$, we did find a monotonic relationship between degree of satisfaction with the course and increase in ethical awareness $(P=0.0164)$ when we calculated the Spearman's rank correlation coefficient for that relationship (Table 3).

An inverse correlation between greater awareness of the ethics content of the training and the degree of satisfaction with the course was suggested based on the coefficient of -0.4753 . This numerical finding was re- 
Table 3. Correlations of degree of satisfaction with the training course with change in ethical awareness and increase in surgical skill

\begin{tabular}{|c|c|c|c|c|c|c|c|c|c|c|}
\hline & \multirow{2}{*}{$\begin{array}{c}\text { No. of } \\
\text { Respon- } \\
\text { dents }\end{array}$} & \multirow{2}{*}{$\begin{array}{c}\text { Simple } \\
\text { Coeffi- } \\
\text { cient }\end{array}$} & \multicolumn{2}{|c|}{ Assumed 95\% CI } & \multicolumn{2}{|c|}{ Assumed 99\% CI } & \multirow[b]{2}{*}{$\begin{array}{l}\text { Degree of } \\
\text { Freedom }\end{array}$} & \multirow[b]{2}{*}{$\begin{array}{l}\text { Statistical } \\
\text { Value }\end{array}$} & \multirow[b]{2}{*}{$P$ value } & \multirow[b]{2}{*}{ Det. } \\
\hline & & & $\begin{array}{l}\text { Upper } \\
\text { Limit }\end{array}$ & $\begin{array}{l}\text { Lower } \\
\text { Limit }\end{array}$ & $\begin{array}{l}\text { Upper } \\
\text { Limit }\end{array}$ & $\begin{array}{l}\text { Lower } \\
\text { Limit }\end{array}$ & & & & \\
\hline $\begin{array}{l}\text { Degree of satisfaction vs. mean } \\
\text { diff. in animal ethics }\end{array}$ & 25 & -0.4753 & -0.0987 & -0.7328 & 0.0332 & -0.7883 & 23 & 2.5906 & 0.0164 & {$[*]$} \\
\hline $\begin{array}{l}\text { Degree of satisfaction vs. mean } \\
\text { diff. in increase in surgical skill }\end{array}$ & 25 & 0.2331 & 0.5752 & -0.1785 & 0.657 & -0.3028 & 23 & 1.1494 & 0.2622 & [ ] \\
\hline
\end{tabular}

Det: Determination.

flected in the opinions and comments trainees entered in the free space on the bottom of the questionnaire sheet. A strong and constant theme in these comments was the opinion that more time should have been spent on technical practice.

Staging surgical training exercises in wet laboratories is undeniably beneficial. The major benefit is the opportunity afforded to participants to acquire skills away from the hectic schedule of their daily work. However, remembering that physicians are supposed to be benevolent practitioners is an important consideration at training institutions. Achieving a high degree of surgical skill is essential, but this should progress together with the ethical education of doctors.

Based on the results of this study, we consider that trainees increased their awareness of animal ethics after receiving wet-lab with 45 min of training on approaching animals as living beings. Ethical awareness may vary depending on the species being considered; however, wet labs are clearly moving in the direction of raising ethical awareness of life as something that all living beings share. As guidance for future practice, we recommend the inclusion of thought-provoking content on animal ethics and welfare in wet-lab training courses, and consideration of the nature of the training when the use of live animals is involved.

\section{Acknowledgment}

The authors would like to thank the doctors from the gastroenterology and respiratory departments who participated in this training, and the technicians caring for animals in the Animal Research Facility for their support. We would also like to express our appreciation to the many people whose contributions led to an improvement of this training.

This research was funded through a Grant-in-aid for
Scientific Research, Grant for Challenging Exploratory Research 15K12367 for the Establishment and Evaluation of Training to Promote Ethics and Non-technical Skills in a Program for Acquisition of Surgical Skills. The authors have no conflict of interest to disclose.

\section{References}

1. Bath, J., Lawrence, P., Chandra, A., O’Connell, J., Uijtdehaage, S., Jimenez, J.C., Davis, G., and Hiatt, J. 2011. Standardization is superior to traditional methods of teaching open vascular simulation. J. Vasc. Surg. 53: 229-235.e2,. [Medline] [CrossRef]

2. Brunt, L.M., Halpin, V.J., Klingensmith, M.E., Tiemann, D., Matthews, B.D., Spitler, J.A., and Pierce, R.A. 2008. Accelerated skills preparation and assessment for senior medical students entering surgical internship. J. Am. Coll. Surg. 206: 897-904, discussion 904-907. [Medline] [CrossRef]

3. Clifford, P., Melfi, N., Bogdanske, J., Johnson, E.J., Kehler, J., and Baran, S.W. 2013. Assessment of proficiency and competency in laboratory animal biomethodologies. J. Am. Assoc. Lab. Anim. Sci. 52: 711-716. [Medline]

4. Hansen, L.A. 2014. Animal laboratories are not needed to train medical students. J. Surg. Educ. 71: 454. [Medline] [CrossRef]

5. Hudáková, Z., Zięba, H.R., Lizis, P., Dvořáková, V., Cetlová, L., Friediger, T., and Kobza, W. 2016. Evaluation of the effects of a physiotherapy program on quality of life in females after unilateral total knee arthroplasty: a prospective study. $J$. Phys. Ther. Sci. 28: 1412-1417. [Medline] [CrossRef]

6. Iki, Y., Noda, M., Kudoh, K., Sueta, T., Kanehira, M., Ito, T., Matsuda, Y., Okada, Y., and Unno, M. 2017. [Surgical Training Utilizing Swine Under General Anesthesia and Animal Ethics]. Kyobu Geka 70: 329-333. (in Japanese) [Medline]

7. Kehinde, E.O. 2013. They see a rat, we seek a cure for diseases: the current status of animal experimentation in medical practice. Med. Princ. Pract. 22:(Suppl 1): 52-61. [Medline] [CrossRef]

8. Noda, M., Mizuma, M., Maeda, S., Sakurada, A., Hoshikawa, Y., Endo, C., Okada, Y., Unno, M., Kasai, N., and Kondo, T. 2012. Presented at the 64th Annual Scientific Meeting of the Japanese Association for thoracic surgery: wet-lab training for thoracic surgery at the laboratory animal facili- 
ties. Gen. Thorac. Cardiovasc. Surg. 60: 756-759. [Medline] [CrossRef]

9. Sadideen, H., Alvand, A., Saadeddin, M., and Kneebone, R. 2013. Surgical experts: born or made? Int. J. Surg. 11: 773-778. [Medline] [CrossRef]

10. Torricelli, F.C.M., Guglielmetti, G., Duarte, R.J., and Srougi,
M. 2011. Laparoscopic skill laboratory in urological surgery: tools and methods for resident training. Int. Braz J Urol 37: 108-112. [Medline] [CrossRef]

11. Voice of Pro-Test. 2013. Voice of Pro-Test. Nature 497: 158. [Medline] [CrossRef] 